
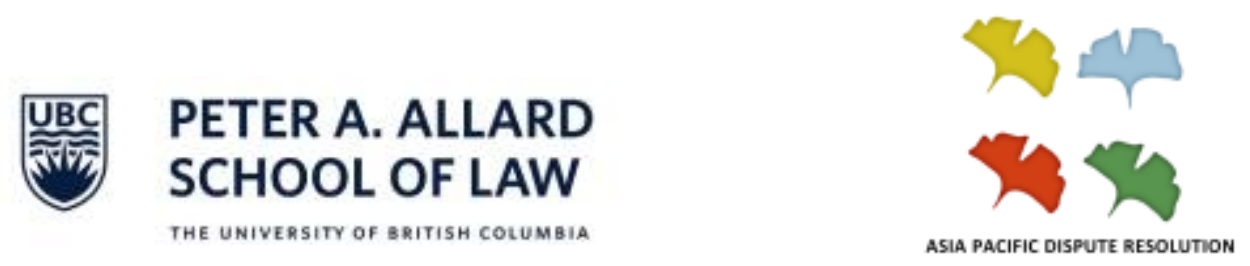

\title{
Inter-Regional Targeted Assistance Program in China and its Relevant Legal Issues
}

\author{
Shuliang Wang \\ Law Institute, Shanghai Academy of Social Sciences
}
APDR Working Paper Series
Volume 2 Number 1

ISSN 2371-6304

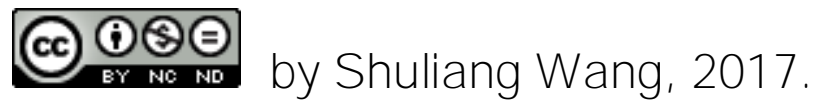

This article is made available as part of the Asia Pacific Dispute Resolution Working Paper Series and is licensed under a Creative Commons Attribution-NonCommercialNoDerivatives 4.0 International License (CC-BY-NC-ND) 


\title{
INTER-REGIONAL TARGETED ASSISTANCE PROGRAM IN CHINA AND ITS RELEVANT LEGAL ISSUES
}

\author{
Shuliang Wang \\ Law Institute, Shanghai Academy of Social Sciences
}

The Inter-Regional Targeted Assistance Program (ITAP) was established since the founding of the People's Republic of China (PRC) by the central government in order to connect the economically and culturally advanced provinces and regions with selected less developed provinces and regions, and to provide financial assistance and other support to prompt their economic growth. Since the implementation of the 'Reform and Opening-up' policy, the ITAP has advanced into a robust national policy and has been extensively implemented in China. The ITAP has played an enormous role in diminishing the economic gap between the rich and the poor regions, in timely completion of large infrastructure construction projects, and in assisting with the recovery and reconstruction after major natural disasters. The Chinese ITAP has been acknowledged by governments and media in many countries and areas as a unique assistance program with socialist characteristics created by China.

However, the ITAP must be legitimatized by laws and regulations, especially when the Fourth Plenary Session of the 18th Communist Party of China (CPC) Central Committee has established the 'comprehensive promotion of the rule of law' as the overall goal and major task in China. According to the requirements of the rule of law, all administrative behaviors of the government should be conducted according to laws and regulations; ${ }^{1}$ thus, the Chinese government should plan, examine, and supervise the government's administrative behavior in the ITAP.

\footnotetext{
${ }^{1}$ On October 23, 2014, The Fourth Plenary Session of the Eighteenth Central Committee adopted "CPC Central Committee Decision concerning Several Major Issues in Comprehensively Promoting the Rule of Law," which pointed out, "Comprehensively carry out administrative functions according to the law. Perfect legal structures for administrative organization and administrative procedure, advance the creation of statutes for bodies, functions, powers, procedures, and responsibilities." Chinese Communist Party News, 29 October 2014, available at http://cpc.people.com.cn/n/2014/1029/c64387-25927606.html, accessed 28 August 2017.
} 


\section{The Birth and Growth of the ITAP}

The ITAP has been proposed by the central government as a basic national policy, and its model and implementation capacity have been developed over a long period of time.

1. ITAP as a regional collaboration and support initiative

When the PRC was founded in 1949, the economic development in different areas of China was very uneven, the production areas of raw materials were at big distance from industrial areas, the industries were distributed very unevenly, and ethnic minority areas were significantly less developed. To change this situation, between the mid-1950s to the early-1960s, the Chinese central government established a collaboration and support mechanism to offer assistance from the more developed eastern coastal areas and provinces to the less developed western border provinces; mainly from Shanghai, Tianjin and other eastern coastal areas to Shaanxi, Xinjiang, Inner Mongolia, and other western regions and border areas. While the collaboration and support mechanism was similar to an ITAP, the concept of ITAP was not officially proposed. For example, after the Tangshan earthquake in 1976, the central government implemented a collaboration and support mechanism throughout the country to help Tangshan recover from the disaster and rebuild its city efficiently and fast. The collaboration and support mechanism is the embryonic form of the ITAP.

2. ITAP in the construction of coastal and ethnic minority areas

From April 25 to May 11, 1979, the CPC Central Committee held the National Border Work conference in Beijing. The ITAP was firstly put forward at this conference. Wu Lanfu, Member of the Political Bureau of the CPC Central Committee and Secretary of the Central United Front Work, put forward in his report to the General Assembly that "the state will strengthen the construction of border areas and ethnic minority areas, increase capital and material investment, and arrange for the prosperous provincial and municipal counterparts to support the border areas and ethnic minority areas." The meeting identified several eastern economically developed provinces and municipalities to assist five costal and ethnic minority 
provinces. The No. 52 Document issued at this conference officially put forward a national policy for Inter-Regional Targeted Assistance, namely, "organizing the economically developed provinces and municipalities to assist their targeted coastal and ethnic minority areas, which included Beijing's ITA to Inner Mongolia, Hebei's ITA to Guizhou, Jiangsu's ITA to Guangxi and Xinjiang, Shandong's ITA to Qinghai, Tianjin's ITA to Gansu, Shanghai's ITA to Yunnan and Ningxia, the national ITA to Tibet."

Thus, the ITAP was officially established as a national policy to promote the economic and social growth of the coastal and ethnic minority areas, and to further develop them in the subsequent practice. For example, since 1979, when the National Border Work conference set up the national ITAP in Tibet, the central government held five national symposiums on Tibet's ITA work (in 1980, 1984, 1994, 2001, and 2010), which provided strong support to Tibet's social and economic development. The ITAP has become an important approach to change the impoverishment of coastal and ethnic minority areas.

\section{Further development of the ITAP}

With continuing implementation and practice, the ITAP has gradually been institutionalized with increasing assistance projects, investment, and personnel input. The receiving provinces in the ITAP have benefited economically from the long-term assistance from their pairing provinces. The basic setup of ITAP was formed throughout the country as a targeted assistance from the eastern economically developed provinces to the western less developed provinces.

The ITAP could be adjusted according to certain special circumstances. For instance, in 2009 after the 'July 5th incident', ${ }^{2}$ to change Xinjiang's social and economic 'backwardness' and protect the long-term stability of Xinjiang, the central government decided to increase the support for Xinjiang's reconstruction by assigning Beijing, Tianjing, Shanghai, Guangdong, Liaoning, Shenzhen, and other 13 provinces to take on the ITA responsibility.

\footnotetext{
2 This incident was the Riot in Urumqi, the capital city of Xinjiang, Uighur Autonomous Region on July 5, 2009. See: "Urumqi Municipal Government held a press conference to introduce '7.5' incident," China.eastday.com, July 7, 2009, available at http://news.eastday.com/c/20090707/u1a4488052.html, accessed 28 August 2017.
} 
In addition to the ITAP between the eastern and the western provinces, especially the border and ethnic minority areas, the ITAP has been widely implemented in two other major fields, which will be discussed below.

\section{a) ITAP application in the construction of the Three Gorges Dam Project}

The Three Gorges Dam Project, ${ }^{3}$ as the largest hydro power station in China, and in the world, involved major challenges in resident relocation of 19 counties or towns in Hubei and Sichuan (Chongqing) due to the construction of the reservoir, and the sustainable economic and social progress in these affected areas. These difficulties have been hard to address by only relying on Hebei and Sichuan, so the central government established the ITAP to support the construction of the Three Gorges Dam Project.

On March 27, 1992, the Office of State Council issued "Notice to Develop the ITAP for the Reservoir Migrants in the Three Gorges Dam Project" (Guoban fa [1992] No. 14) to initiate the ITAP for the Three Gorges Dam Project. On August 19, 1993, the State Council issued "Regulation on the Settlement of Three Gorges Dam Project Migrants" (Guowuyuan ling [1993] No. 126) to encourage and support the State Council ministries and the relevant provinces and areas to conduct the ITAP for the Three Gorges Dam Project. On February 21, 2001, the State Council revised and publicized "Regulation on the Relocation of Three Gorges Project Migrants" (Guowuyuan ling [2001] No. 299) to clarify the responsibilities of each ITA participating province and area in the Three Gorges Dam Project.

In April 1994, "The Notice of State Council on Further Settlement of Reservoir Migrants in Three Gorges Dam Project by ITAP” (Guofa ban [1994] No. 58) was issued to establish an ITAP to arrange 26 provinces, municipalities, and large and medium-sized cities to support the 23 submerged counties in the reservoir area in Changqin and Hubei. The Three Gorges Dam Project

\footnotetext{
3 The Three Gorges hydropower station has an installed capacity of 22 million 500 thousand kilowatts and is the largest hydropower station in the world. See China Youth Daily, 5 July 2012, available at http://zqb.cyol.com/html/2012-07/05/nw.D110000zgqnb_20120705_6-01.html, accessed 28 August 2017.
} 
migrants received ITA from all the provinces, municipalities, and cities, and each county flooded by the reservoir got ITA from one specific province. The ITAP was not only directed at the relocation of residents in the flooded areas by the reservoir, but also provided policy support from the national ministries and commissions, and investment oriented economic assistance. With the ITAP, the millions of migrants in the Three Gorges Dam Project were relocated on schedule, the construction proceeded well and the GDP and per capita production value have been greatly increased in the Three Gorges Dam Reservoir areas.

In 2014, the Three Gorges Dam Project Office ${ }^{4}$ submitted to the State Council "The Plan on the Three Gorges Dam Reservoir Area National ITAP (2014-2020)”. The Plan was approved immediately by the State Council and thus initiated the further implementation of the ITAP in the Three Gorges Dam reservoir area. The ITAP played an irreplaceable role in China's Three Gorges Dam Project construction.

\section{b) ITA application for the Wenchuan earthquake reconstruction}

On May 12, 2008, an 8.0 magnitude earthquake hit Sichuan, which caused the most destructive and extensive damage and required the most difficult disaster rescue operation. In order to promptly shelter the disaster victims and reconstruct the earthquake affected areas, the central government implemented the ITAP, which is the first time China introduced the ITAP in the recovery and reconstruction after a major disaster.

On May 20, 2008, the China Ministry of Civil Affairs issued the "Notice of Implementation of ITA to Support the Recovery Work from Wenchuan Major Earthquake", and "Emergency Notice of ITA to Support the Sichuan Wenchuan Earthquake Disaster Area.” On May 26, 2008 the CPC Central Committee Political Bureau held a meeting to study the implementation of the earthquake rescue and post-disaster reconstruction, and decided to "establish ITA mechanism, organize the power of the country, and speed up the restoration and reconstruction processes." On May 27, 2008 the State Council Earthquake Recovery Headquarters clearly stated to "assign

\footnotetext{
4 The State Council Three Gorges Dam Construction Committee Office is the main administrative office of the State Council Three Gorges Dam Construction Committee.
} 
one province to assist one county in the earthquake area, and several provinces to assist one city (prefecture), to speed up the recovery and reconstruction after the earthquake."

Immediately on June 8, 2008, the State Council issued "Regulation on the Recovery and Reconstruction of the Wenchuan Earthquake Area" (Guowuyuan ling [2008] No. 526), which confirmed the implementation of the ITAP in the earthquake area by making administrative regulations. On June 11, 2008 the State Council publicized the "Plan on the ITAP for the Recovery and Reconstruction after Wenchuan Earthquake” (Guobanfa [2008] No. 53), which specified that 19 provinces and cities would be included in the ITAP, and other counties (cities, districts) not covered by the ITAP but affected by the earthquake would receive ITA support from their provincial governments, the ITAP would be implemented for three years and the yearly amount of ITA financial support from each supporting province would be no less than $1 \%$ of its previous year's local revenue.

The recovery and reconstruction after Wenchuan earthquake made remarkable achievements. The reconstruction was completely finished within three years. The implementation of ITAP in Wenchuan earthquake recovery and reconstruction has proven to be effective and successful.

In all, the ITAP has undergone a long development since its birth, and has been improved to be a mature assistance mechanism. The ITAP is currently implemented in the following three circumstances: 1) support the border and ethnic minority areas, and economically less developed areas, such as Tibet and Xinjiang; 2) support national major infrastructure projects, such as migrant settlement and economic recovery in the Three Gorges Reservoir; and 3) recover and reconstruct the areas affected by major natural disasters, such as the Wenchuan earthquake.

\section{Evaluation of the Current ITA Model in China}

1. ITA in the Socialist State with Chinese Characteristics

The ITAP has been formulated and developed within the Chinese socialist system and thus demonstrates Chinese socialist advantages in social and economic development. 
a) ITAP is established to diminish the regional economic discrepancy, promote collaboration and prosperity throughout the country and support the development of ethnic minority areas

Due to its history, geographical location, natural conditions and other reasons, China's central and western interior provinces and border provinces have consistently been less developed, while the coastal areas have been relatively more developed and prosperous. In spite of policy, financial, and personnel support from the central government, the development of these less developed areas still greatly lags behind compared to the coastal areas because of their vast geographical area and inadequate economic foundation. To make it worse, since China has implemented the 'reform and opening-up' policy, the increased investment and human resources input in the coastal areas has increased the development gap between the coastal and less developed areas. The long term disadvantage of the minority areas has generated social conflicts and endangered the stability and consolidation of the border areas. This problem must be addressed by the CPC as the ruling party in China since "the greatest advantage of a socialist country is to achieve common prosperity, which manifests the essence of socialism." 5 Deng Xiaoping, the Chief Leader of China's 'reform and opening-up' policy, put forward an approach to " let part of the country develop faster and other part of the country develop slower, and then the well-developed areas will assist the less developed areas and finally achieve common prosperity." ${ }^{\prime 6}$ Deng's statement confirmed the regional development imbalance between various areas in China while insisting on the goal of national prosperity. He emphasized the responsibility of the well-developed areas to support the less developed areas to achieve national prosperity, which has legalized the implementation of ITAP in China. With the targeted assistance from the coastal provinces to the interior and border provinces, the less developed areas received resources to enhance people's livelihood, improve the infrastructure, and increase local construction projects, so that the recipient provinces develop their potential for sustainable development. If the ITAP is implemented continually, the gap between the supporting provinces and receiving provinces is expected to be greatly narrowed, the border ethnic minority areas can

\footnotetext{
${ }^{5}$ Selective Works of Deng Xiaoping, Vol. 3 (Renmin Press, 1993) p. 364.

${ }^{6}$ Ibid, p. 374.
} 
quickly develop their economy and eliminate long-term poverty, and China can finally achieve balanced development throughout the country. Balanced development in China is essential to keep cohesion of the ethnic minorities.

\section{b) ITAP is mutual support and collaboration throughout the nation}

China has featured its practice and experience in the mutual support and collaboration across the country since the founding of the PRC. Under the guidance and implementation of this principle, China will be able to hold together the power of the country to overcome the difficulties in largescale construction. China is a geographically large country, therefore some of the major construction and infrastructure projects often require the efforts from several provinces and simultaneously benefit several provinces; thus, collaborative efforts from various provinces are required to implement these projects and overcome the difficulties. For instance, the Three Gorges Hydropower Station was a very large project. Its functions of power generation, flood control, shipping, irrigation, and others benefit regions far beyond the surrounding areas and regions, with some benefiting half of the regions in China. Thus, the Three Gorges Dam Project is a national project in terms of its importance and benefits, and should be managed at the national level.

As the Three Gorges Dam Project benefits far beyond the provinces and regions where the construction was conducted, it is not fair to solely rely on these provinces and regions, such as Hubei and Sichuan (Chongqing), to take on the relocation of residents from flooded areas and other difficult tasks due to the construction. Therefore, the Chinese government emphasized on the collaborative efforts throughout the country and decided to introduce the ITAP, requiring the participating provinces and municipalities to work together on the relocation of the residents. Twenty-six provinces, municipalities, and large and medium-size cities were assigned respectively to the twenty-three counties which were flooded for the construction of the Three Gorges Dam Project. A national ITAP was established to help relocate the residents from the Three Gorges Dam reservoir area, and a provincial ITAP was set up to financially support the flooded areas. Thus, the reservoir residents relocation, the hardest problem to address in the construction of the largest hydro power station in the world, was well implemented. 
c) The ITAP reflects the spirit of 'when disaster strucks, help comes from all sides'

The Wenchuan earthquake on May 12, 2008 was one of the deadliest natural disasters, and the earthquake-stricken area could have never been recovered and reconstructed without help from other sides. To immediately establish temporary shelters for the victims and start the reconstruction after the earthquake, the Chinese local governments not only transported large amounts of supplies, allocated funds, and dispatched a large number of rescue teams to the affected areas, but also implemented the ITAP, in order to acquire the national power and strength to speed up the recovery and reconstruction processes. The State Council promulgated "Wenchuan Earthquake Disaster Recovery and Reconstruction Regulations." The General Office of the State Council issued "Wenchuan Earthquake Disaster Recovery and Reconstruction ITAP," and established the guidelines for the ITAP, the specific implementation plan including the tasks and support facilities, and detailed tasks and responsibilities. The 19 supporting provinces and cities took actions promptly with some completing the tasks ahead of schedule. Simultaneously, Inner Mongolia, Hainan, Qinghai and other provinces (regions), Guiyang City, and some other provinces and cities, which were not required to participate in the ITAP, also took the initiative to participate in the ITAP. Three years after the Wenchuan earthquake, the disaster area has been basically recovered and reconstructed, and the central government provided 300 billion yuan for recovery and reconstruction. Nineteen provinces and cites invested 84.38 billion yuan in 4,121 support and assistance projects in their targeted assistance areas. ${ }^{7}$ The successful recovery and reconstruction of Wenchuan earthquake affected area could not have been possible without the implementation of the ITAP.

\section{d) ITAP functions not only as a lengthy and sustainable support but also as urgent aid}

As discussed above, ITAP was initially established mainly to support the economic and social development of the border areas and ethnic minority areas, thus, rather than providing short-time

\footnotetext{
7 See speech by Mu Hong, Vice Director of National Development and Reform Committee, at a press conference on May 10, 2010. Available at http://www.china.com.cn/news/2011-05/10/content_22530503.html, accessed 28 August 2017.
} 
aids, the Program assists these areas to have sustainable and continuous development. However, when ITAP was implemented for disaster recovery and reconstruction, and major infrastructure construction projects, it functioned as a short-term, emergent, and special measure to support the ITA receiving provinces on specific cases.

e) ITAP as executive initiative issued by the government

The ITAP was created by executive order when China's economy was mainly centrally planned. To present, the ITAP is still an assistance program planned by the central government and implemented by the well-developed regions to support the economic growth of the less developed areas and ethnic minority regions, to assist with the construction of major infrastructure projects, and to assist with the recovery and reconstruction of regions suffering from natural disasters. The central government allocates ITAPs to local provinces as executive tasks and responsibilities. The supporting local governments not only assume responsibilities for the payment of taxes to the central government, but are also obliged to transfer part of their revenues to the ITA receiving local governments. Therefore, the ITAP is labeled as having a planned-economy character, and also illustrates the governance of the current Chinese government.

\section{f) ITAP's conflict with the rule of law}

The ITAP runs into several issues conflicting with the rule of law principle in China.

i. ITAP is not regulated in Chinese law.

The ITAP has become an important national policy in social governance in China, and it has to be justified why the central government can force the local government to take part in an ITAP, and why the local government must accept the assignment. The Constitution of the PRC does not have any provisions on inter-regional targeted assistance (ITA). The Law of PRC on Regional National Autonomy specifies in Article 64 that "superior state organs shall organize, support, and encourage economic and technical cooperation and multi-level and multi-faceted ITA from 
economically developed areas and national autonomous areas, and support, help, and promote the development of economy, education, science and technology, culture, health, and sports in national autonomous areas." This article is problematic to justify an ITAP as it only mentions that the ITA is the responsibility of the superior state organ instead of supporting provinces and cities through ITA. Furthermore, even the superior state organs' ITA responsibility is not included in the Constitution.

ii. Current ITA policy made by the State Council is in conflict with the pertaining legislations

The State Council issued the "Plan on the Implementation of ITAP in Recovery and Reconstruction after the Wenchuan Earthquake" and specified that "the supporting provinces and cities must provide to the receiving provinces and cities assistance that is no less than $1 \%$ of their previous year's revenue." However, according to the PRC's Budget Law, ${ }^{8}$ "local governments at or above the county level must report the fiscal budgets and financial accounts to the People's Congress at the same level, and are not allowed to modify and revoke them. The People's Congress at the same level has the right to examine, approve, and supervise the fiscal budgets, financial statements, and accounts of the local government, and have the right to change or revoke inappropriate decisions or orders made by executive departments of the same level or subordinate governments. The State Council's administrative regulation is in conflict with the Budget Law.

iii. The Planning, Implementation, and Operation of the ITAP are out of the supervision of the People's Congress.

China's ITAPs often involve a large amount of funds. For example, Shanghai invested 2.196 billion yuan for 2,711 ITAPs in eight receiving areas during the five years under the "11th Five-

\footnotetext{
8 On March 26, 1994, the 8th session of the second meeting of the NPC passed PRC's Budget Law, and in August 31, 2014, the 12th session of the 10th meeting of the NPC Standing Committee modified the law. Budget Law of the People's Republic of China (revised 2014), available at http://jrs.mof.gov.cn/ppp/zcfbppp/201410/t20141030_1155100.html, accessed 28 August 2017.
} 
year Plan". 9 According to The Second National Yuanjiang Work Conference, the total investment to ITAPs in Xinjiang in 2014 accounted for more than 10 billion yuan. However, these huge amounts of investment and transfer between local governments have never been recorded in the "State Council Work Report" to the National People's Congress. Local governments only reported the ITAPs to the local People's Congress in very brief sentences, even shorter than a paragraph. The lack or briefness of the government reports to the People's Congress has made it impossible for the People's Congress to do an effective supervision, which tends to result in corruption and waste of resource in the implementation of ITAPs.

In all, the lack of legislation on ITAP, the conflict between administrative regulations and laws, and the lack of supervision are the main problems with ITAP.

\section{Legalization of ITAP}

The rule of law was introduced in the 15th Party Congress of CPC in 1997, and was incorporated into PRC's Constitution two years later. The fourth plenary of 18th Party Congress of CPC focused on the implementation of rule of law in China and made strategic plans to establish the rule of law in China. The rule of law principle requires that governments' behaviours must be performed according to the law. Accordingly, the ITAP, as a governance policy created in planned-economy China, must be legalized according to the governance of the rule of law. It could be achieved by taking the following steps:

\section{Legislations}

a) The constitution should be revised to incorporate the relevant regulations on ITAP, namely, the economically well-developed areas should take on the responsibility to assist the less developed areas, minority areas, major construction projects, and areas suffering from national disaster.

\footnotetext{
${ }^{9}$ See the Shanghai ITA Program 12th Five-year Plan in "Shanghai's counterpart support and cooperation and exchange "Twelfth Five - Year Plan."” Available at http://xzb.sh.gov.cn/node2/node4/n1021/n1027/n1065/u1ai105779.html, accessed 28 August 2017
} 
b) China should make new laws and regulations, or revise laws and regulations to solve the conflicts between the administrative regulations and laws in the current ITA normative framework.

2. Governments

a) China's national and local governments should set up specialized organs to conduct ITAP

i. The State Council shall establish a unified department to organize and coordinate the national ITAPs.

In January 1983, the State Council approved and publicized "The Minute of the Economic and Technical Cooperation between the Well-Developed Provinces and Cities and Minority Areas" (Guofa [1983] No. 7), and confirmed that the ITAP should be jointly conducted by the State Economic Commission (mainly responsible), State Planning Commission, and the State Ethnic Affairs Commission. ${ }^{10}$ However, the joint and coordinative leadership of several commissions cannot be exercised independently. The State Council should establish a specialized organization to take on the leadership of organizing and coordinating the ITAPs in the country. This organ should have the following key responsibilities: make a national ITA plan; approve major national ITAPs; supervise the implementation and outcomes of provincial ITAPs; and report to the query and supervision of National People's Congress.

ii. The ITA supporting provincial or municipal governments should establish a specialized organ to organize ITAPs in provinces or cities

The ITAPs are currently conducted by various organs at the provincial or municipal levels. For example, ITAPs are conducted by the Development and Reform Committee in Beijing and Jiangsu province, by Cooperation and Exchange Office in Shanghai, by Economic Cooperation

\footnotetext{
10 The State Economic Commission was cancelled and incorporated into Minister of Commerce. The State Planning Commission was renamed as the State Development and Reform Commission.
} 
and Exchange Office in Zhejiang. These organizations belong to various departments of the local governments and are not specialized in administering the ITAPs. Thus, the author suggests the provincial and municipal governments to set up specialized organs responsible for the province and municipal ITAPs by performing the following duties: implement the national ITA plan issued by the State Council; represent the supporting provinces or cities to communicate with the receiving provinces or cities; monitor the ITA funding usage; represent the government to transfer ITA supplies; and respond to the query of the People's Congress at the same level of the ITAP.

iii. The receiving provinces and autonomous regions should set up specialized organs to be responsible for receiving ITAPs

The receiving provinces and cities have not established any specialized organs for the ITAPs, and some provinces and municipalities only established a leading group to assist the implementation of ITAPs, which are not able to fully take on the responsibility of ITA work. Therefore, specialized organs should also be established to conduct the ITAPs, with the main duties as follows: submit ITA applications to the State Council; represent the local government to communicate with the other provinces and cities in the management of the ITAP; assist with the transfer of assistance funding; represent local governments to review and accept the ITA supplies; and respond to the query from the People's Congress of the same level.

b) The State Council and local governments should report the ITA work to the National People's Congress or to the People's Congress of the same level.

Since the governments' reports to the People's Congress have barely included details of the ITAP, the People's Congress cannot fully examine and monitor the implementation. The government should work under the supervision of the People's Congress governed by the principle of the rule of law, thus the State Council and local governments should incorporate a special part in the reports to clarify the governments' work on the ITAP, so that the People's Congress can monitor it effectively. 
In all, the ITAP has become an important social and state governance model in China after decades of operation and has played an imperative role in the economic growth of border and ethnic minority areas, the construction of Three Gorges Dam Project, and the rescue and reconstruction after Wenchuan earthquake. However, the ITAP must be implemented according to the rule of law by setting up the legal framework for ITAP to promote sustainable development and become a successful assistance model for foreign countries to learn from. 